\title{
A Simplified Technique to Fabricate Hollow Obturator Using Light-curing Resin with Cheek Plumpers Using Functional Impression Technique: A Clinical Report
}

\author{
Rahul Bahri ${ }^{1}$, Vijaya Kumar Rajamani ${ }^{2}$, Eraiah Mahesh Gowda ${ }^{3}$
}

\begin{abstract}
Rehabilitation of maxillary defects using obturator prosthesis helps in restoration of form, function, and esthetics. It obturates the oronasal communication improving phonetics and prevents nasal regurgitation of food and fluids. Successful obturator prosthesis relies on an accurate impression of defect site and a well-fitting definitive prosthesis with cast partial denture (CPD) framework. This requires precision and meticulous care at every step during the fabrication of the prosthesis. A functional impression allows physiological recording of defect site within anatomical limitations and fabrication of well-fitting hollow obturator. Esthetics may be restored by using cheek plumpers to provide fullness to the sunken cheek. This clinical report highlights a technique for fabrication of a definitive obturator using a functional impression technique utilizing tissue conditioner, light-curing resin for fabrication of CPD-based hollow obturator, and magnet-retained cheek plumpers to restore form, function, and esthetics in a patient with Aramany class II maxillary defect.
\end{abstract}

Keywords: Cheek plumper, Hollow bulb obturator, LiWa® light-curing resin.

International Journal of Prosthodontics and Restorative Dentistry (2021): 10.5005/jp-journals-10019-1311

\section{BACKGROUND}

The etiology for maxillectomy defects may be congenital (present since birth) or acquired (due to trauma or surgical procedures). More often surgical management of such defects involves resection of the maxilla leading to an oroantral communication, which causes regurgitation of food and fluids from the nose and difficulty in speech. According to GPT-9, an obturator is defined as a maxillofacial prosthesis used to close a congenital or acquired tissue opening, primarily of the hard palate and/or contiguous alveolar/soft tissue structures. ${ }^{1}$ Universally accepted design considerations for fabrication of a definitive obturator are based on Aramany classification where general principles of designing of cast framework have been elaborated for fabrication of prostheses. Resection of maxillary pathologies also leads to a sunken appearance as the supporting bone is removed. This also causes an esthetic setback to the patient leaving altered facial esthetics. This case report presents a technique for fabrication of an obturator using light-curing resin for fabrication of framework and magnet retained cheek plumpers to restore form, function, and esthetics in a patient with Aramany class II maxillary defect using functional impression technique.

\section{Case Description}

A 29-year-old woman was referred to the department of prosthodontics from the ENT department with the chief complaint of difficulty in eating and speech due to oral and nasal communication. Extraoral examination revealed a bilaterally asymmetrical face with the sunken appearance of the cheek on the left side (Fig. 1A). On intraoral examination, the defect measured approximately $3 \times 2.5 \mathrm{~cm}$ extending mesiodistally from the distal surface of the canine to the molar region, involving a hard palate on the left side. The underlying mucosa appeared healthy with no signs of inflammation, the nasal turbines appeared healthy (Fig. 1B).

\begin{abstract}
1,2 Department of Dental Surgery and Oral Health Sciences, Armed Forces Medical College, Pune, Maharashtra, India

${ }^{3}$ Division of Prosthodontics and Crown and Bridge, Department of Dental Surgery and Oral Health Sciences, Armed Forces Medical College, Pune, Maharashtra, India

Corresponding Author: Vijaya Kumar Rajamani, Department of Dental Surgery and Oral Health Sciences, Armed Forces Medical College, Pune, Maharashtra, India, Phone: +91 9674066444, e-mail: dentvk@ gmail.com
\end{abstract}

How to cite this article: Bahri R, Rajamani VK, Gowda EM. A Simplified Technique to Fabricate Hollow Obturator Using Light-curing Resin with Cheek Plumpers Using Functional Impression Technique: A Clinical Report. Int J Prosthodont Restor Dent 2021;11(2):100-104.

Source of support: Nil

Conflict of interest: None

The patient was taken up for rehabilitation and a cast partial denture (CPD)-based hollow obturator was advised as a treatment plan. However, to save on time and laboratory steps, it was decided to use light-curing resin (LiWa, William \& Penn, Germany) for fabrication of the framework for a definitive prosthesis. To address the esthetic concerns of the patient, a magnet retained cheek plumper was planned as a removable attachment to the obturator. The primary impression was made using an irreversible hydrocolloid and a special tray was fabricated. The defect site recording is always a challenge and requires utmost care. Tissue conditioner was used instead of conventional impression material. The advantage of using a tissue conditioner was that being inherently soft; it had a low risk of causing injury to adjacent tissue. Also, it provided sufficient working time to accurately mold and record the defect site. The tissue conditioner (Coe-comfort, GC America) was manipulated as per the manufacturer's directions and was applied directly on the

(c) Jaypee Brothers Medical Publishers. 2021 Open Access This article is distributed under the terms of the Creative Commons Attribution 4.0 International License (https://creativecommons.org/licenses/by-nc/4.0/), which permits unrestricted use, distribution, and non-commercial reproduction in any medium, provided you give appropriate credit to the original author(s) and the source, provide a link to the Creative Commons license, and indicate if changes were made. The Creative Commons Public Domain Dedication waiver (http://creativecommons.org/publicdomain/zero/1.0/) applies to the data made available in this article, unless otherwise stated. 

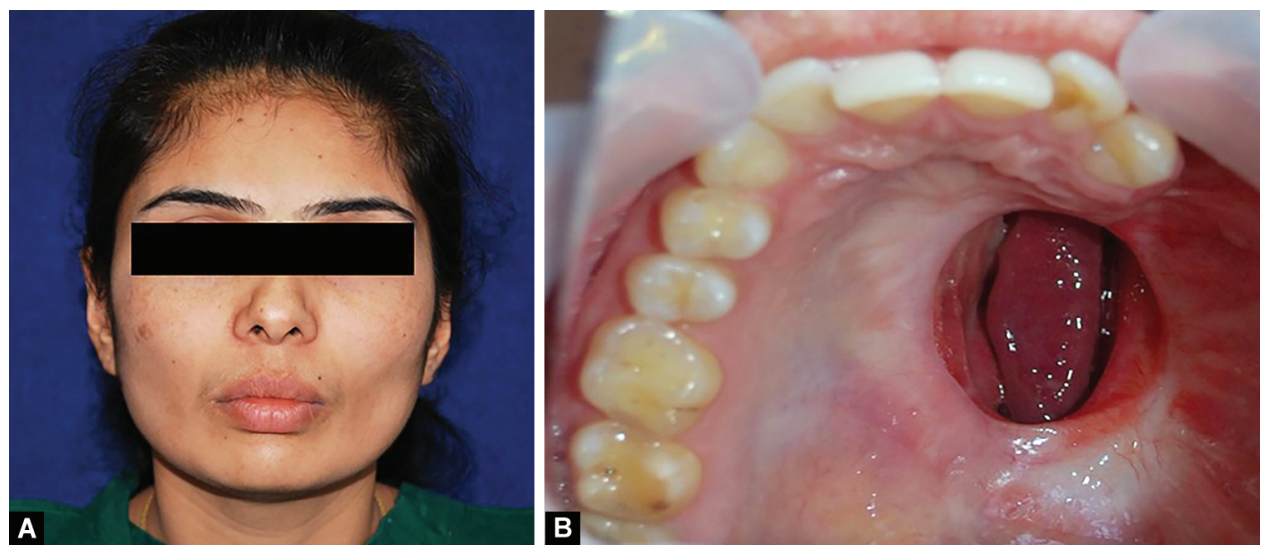

Figs 1 A and B: (A) Preoperative extraoral view shows the sunken appearance of the cheek on the left side; (B) Intraoral defect-left maxilla
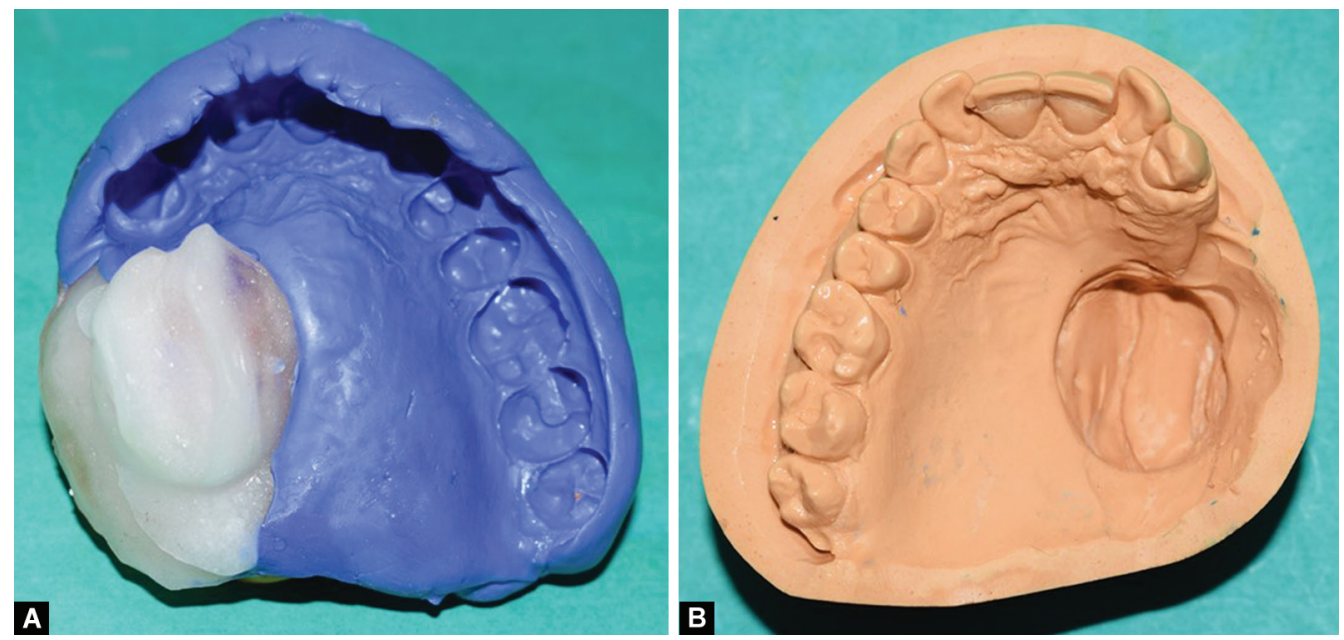

Figs 2A and B: (A) Final impression using tissue conditioner and medium-bodied PVS; (B) Master cast with mouth preparation

special tray in increments. On loading the tissue conditioner, the patient was asked to perform various functional movements for physiological and functional molding of the defect site. After the manufacturer's recommended setting time, the impression was retrieved. The rest seats were prepared as per surveying design. The final impression of the non-defect portion was made using regular-bodied elastomeric impression material (Elite HD + Regular body, Zehrmack) (Fig. 2A). The master cast was fabricated using type IV dental stone (Ultrarock, Kalabhai) and surveying was done to design the cast framework for obturator prosthesis (Fig. 2B). Here on instead of a conventional method of making a duplicate cast for fabrication of the CPD framework, LiWa ${ }^{\circledR}$ lightcuring resin was used. The advantage of this material was saving valuable time, material, and direct trial in the patient's mouth. The various components of the LiWa ${ }^{\circledR}$ light-curing resin-like clasp, connector, and framework were directly adapted over the master cast. This pattern was placed in a curing chamber and was cured as per the manufacturer's instructions. The cured pattern was removed from the master cast and directly tried on the patient for clinical evaluation of fit and extent (Fig. 3). Suitable corrections like addition, removal, and trimming of the wax pattern were carried out at the chairside itself. Upon confirming the fit of LiWa ${ }^{\circledast}$ light-curing resin, it was invested in ethyl silicate investment material. The pattern was subjected to burn out in furnace and cast, following conventional casting technique in induction casting unit. The casting was obtained and the fit was evaluated on the master cast and clinically.

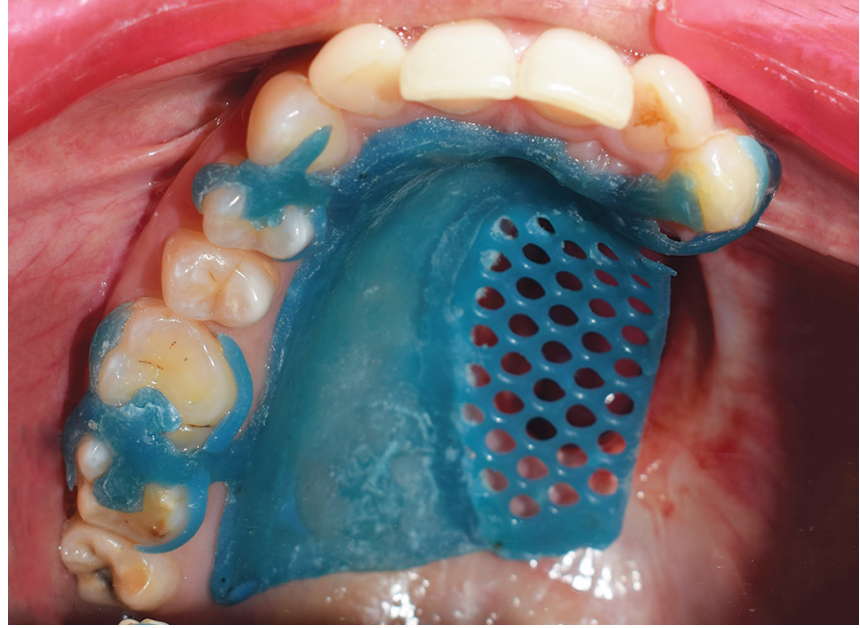

Fig. 3: Try-in LiWa® light-curing resin

The occlusal rim was fabricated over the acrylized framework and maxillomandibular relations were recorded. The cast was mounted on a semi-adjustable articulator and teeth arrangement was done. Try-in was carried out and checked for occlusion in centric relation with no contact during eccentric movement. The framework with bulb extension was processed as per the conventional protocol of a hollow bulb obturator. For fabrication of cheek plumper, 
putty consistency of PVS elastomeric impression material (Elite $\mathrm{HD}+$, Zehrmack Italy) was adopted on the buccal flange area of the obturator, and the patient was directed to perform functional movements like pursing of lips, forceful smiling, and side to side movement of lips (Fig. 4). This impression was processed in heatcured PMMA (DPI, India). After finishing and polishing, magnet (Dyna magnet, Dyna Dental Engineering BV, Netherlands) was attached to the buccal flange area of the obturator in relation to the first molar area (Fig. 5). Another magnet with an opposite pole was attached to the cheek plumper. The obturator with cheek plumper was inserted in the patient's mouth (Fig. 6). A marked improvement in the patient's form, function, and esthetics was noticed (Fig. 7). The patient was given instructions regarding the use and cleaning of the prosthesis and was advised of regular recall.

\section{Discussion}

Various materials and techniques have been mentioned in the literature to fabricate CPD-based obturator prostheses. Light polymerizing pattern waxes like $\mathrm{LiWa}^{\circledR}$ light-curing resin and Metacon light-cured dental wax system; the primotec USA, are emerging as alternatives to the conventional protocol of fabrication of CPD-based prosthesis. Zygomatic and pterygoid

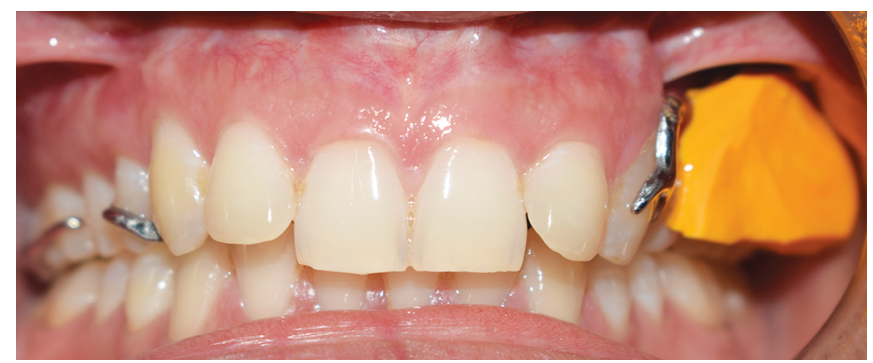

Fig. 4: Impression for cheek plumper (Lt)
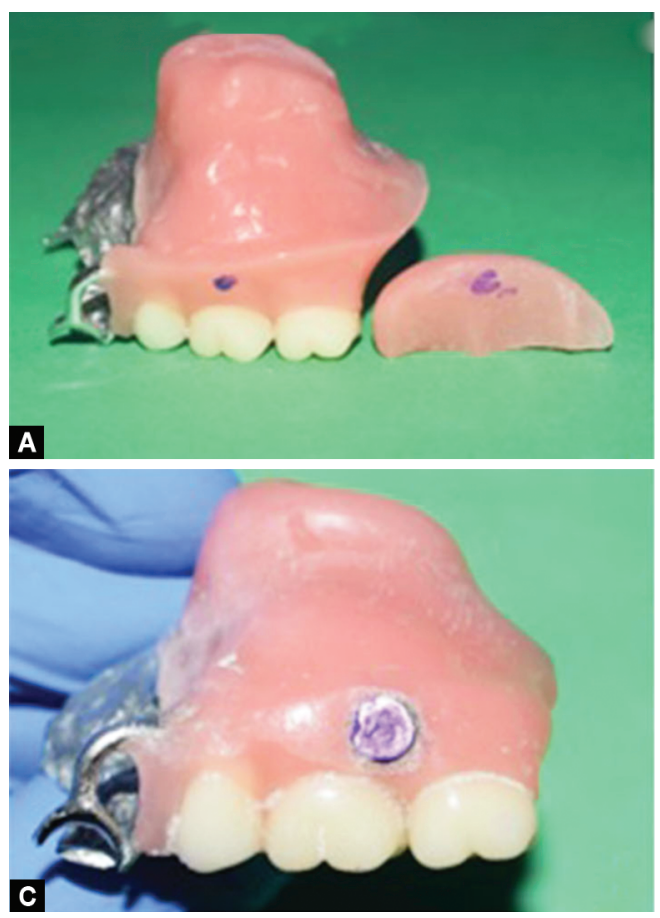

implant-supported obturators with remote anchorage have emerged as alternatives to conventional CPD-based obturators. ${ }^{2,3}$

A well-fitted obturator prosthesis should be able to restore form, function, and esthetics with improvement in speech, respiration, chewing, and deglutition should permit separation between oral and nasal cavities, to provide support for the orbital contents in case of composite defects. ${ }^{4}$ Various authors have advocated the use of tissue conditioners for functional impression techniques. The advantage of using the functional impression technique using tissue conditioner was that all border records of the defect site were obtained by the patient's own movements without any risk of injuring adjacent tissue. The use of tissue conditioner enabled border molding and defect site recording which was guided by extrinsic forces that may not reproduce some functional movements when excessive manual forces are applied. ${ }^{5-7}$ This may be a big advantage when compared with CAD/CAM-based impression techniques. ${ }^{8}$

$\mathrm{LiWa}^{\oplus}$ light-curing resin is a wax-like material used for the fabrication of patterns for partial denture framework for various cast prostheses. ${ }^{9}$ The technique allows simplification of the fabrication process by allowing adaptation of plastic pattern directly on the master cast reducing the laboratory steps like the need for block-out and fabrication of refractory cast. They also permit the try-in of wax patterns intraorally and allow changes at any stage before casting. ${ }^{10}$

Lip or cheek plumper has been recommended in the literature for the management of sunken cheeks. In such cases, use magnetic attachments for cheek plumpers or customized ball attachments have been attempted successfully. ${ }^{11,12}$ In this case, a magnetic attachment was used to serve the purpose and retain two pieces together. Use of detachable lip and cheek plumper allows rehabilitation of facial disfigurement and restoration of esthetics. ${ }^{13}$

Requisite precautions were taken while recording the distobuccal area and the effect of masseter on it allowing space
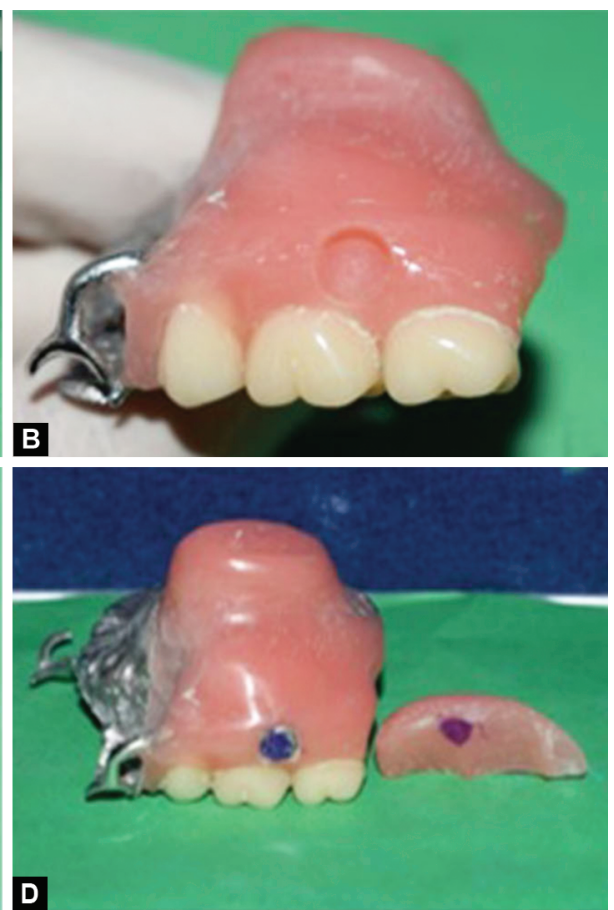

Figs 5A to D: (A) Markings for attachment of magnets; (B) Creating space for magnetic attachment; (C) Magnet attached to the obturator; (D) Markings transferred for attachment of magnet on cheek plumper 

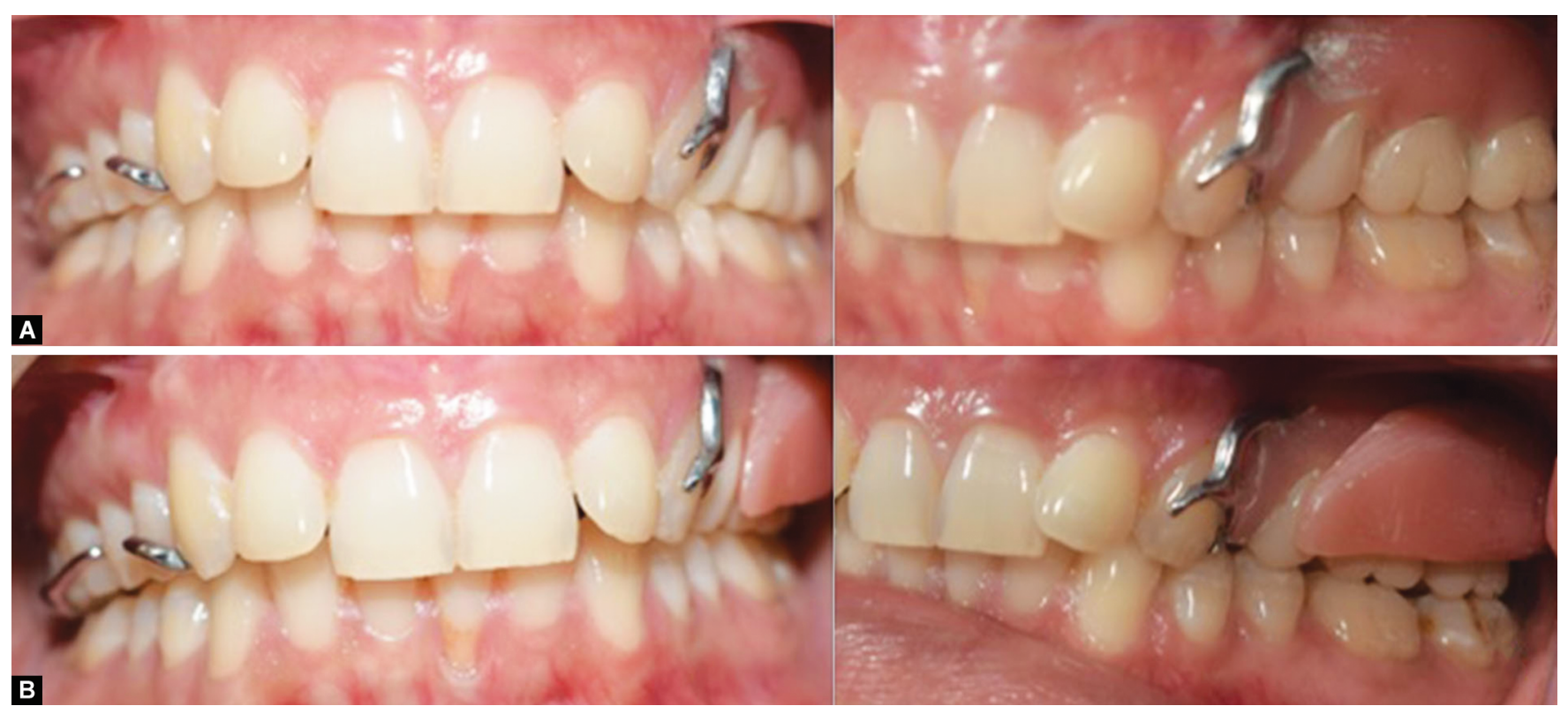

Figs 6A and B: (A) Obturator without cheek plumper in situ; (B) Final definitive obturator with cheek plumper in situ
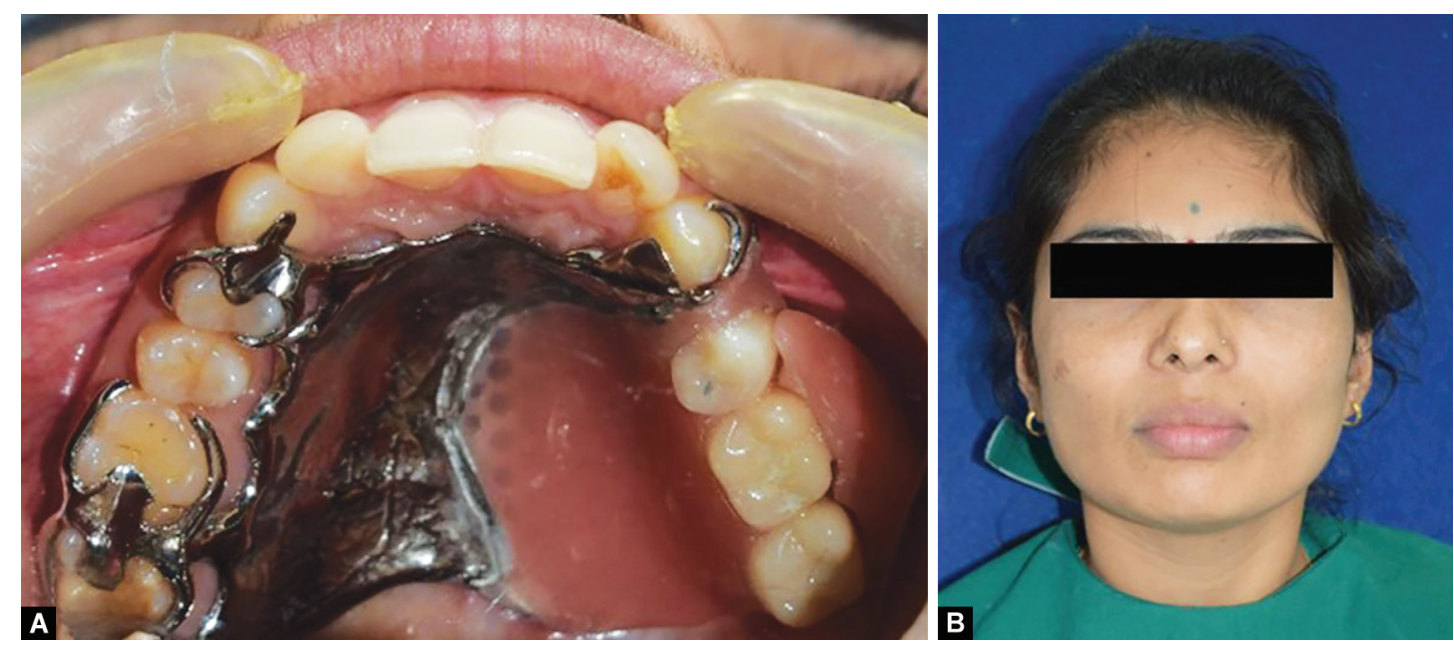

Figs 7A and B: (A) Prosthesis in situ; (B) Postoperative extraoral view

for cheek plumper on the defective side. The cheek plumpers with magnets were fabricated with due care not to increase the weight of the prosthesis.

Rehabilitation of maxillary defects needs a well-fitting CPD framework that can help to obturate the defect and maintain the integrity of the nasal and oral cavity individually. Light-curing resin patterns seem to be a viable alternative that helps in saving the laboratory time and efforts for the fabrication of an obturator prosthesis. Cheek plumpers have been a common treatment option in prosthodontic elevation of the esthetics of patients and can be successfully integrated for patients with altered facial appearance secondary to maxillectomy defects.

\section{References}

1. Ferro KJ, Morgano SM, Driscoll CF, et al. The glossary of prosthodontic terms. J Prosthet Dent 2017;117(5S):e1-e05.

2. Costa-Palau S, Torrents-Nicolas J, Brufau-de Barberà M, et al. Use of polyetheretherketone in the fabrication of a maxillary obturator prosthesis: a clinical report. J Prosthet Dent 2014;112(3):680-682. DOI: 10.1016/j.prosdent.2013.10.026.

3. D'Souza D. Role of implants in maxillofacial prosthodontic rehabilitation. In Current concepts in dental implantology. IntechOpen; 2015.

4. Meenakshi A, Shah D. The obturator prostheses for maxillectomy. SRM J Res Dent Sci 2012;3(3):193-197. DOI: 10.4103/0976-433X. 107402.

5. Razek MK. Assessment of tissue conditioning materials for functional impressions. J Prosthet Dent 1979;42(4):376-380. DOI: 10.1016/00223913(79)90135-5.

6. Vig RG. A modified chew-in and functional impression technique. J Prosthet Dent 1964;14(2):214-220. DOI: 10.1016/0022-3913(64)900824.

7. McArthur DR. Management of the mucolabial fold when developing impressions for complete dentures. J Prosthet Dent 1985;53(1):62-67. DOI: 10.1016/0022-3913(85)90067-8.

8. Michelinakis $G$, Pavlakis M, Igoumenakis D. Rehabilitation of a maxillectomy patient using intraoral scanning impression technology and a computer-aided design/computer-aided 
manufacturing fabricated obturator prosthesis: a clinical report. J Indian Prosthodont Soc 2018;18(3):282. DOI: 10.4103/jips.jips_ 14_18.

9. Takaichi A, Wakabayashi N, Igarashi Y. Prefabricated lightpolymerizing plastic pattern for partial framework. Contemp Clin Dent 2011;2(4):402-404. DOI: 10.4103/0976-237X. 91814.

10. Kar AK, Parkash H, Garhnayak L, et al. Fabricating a hollow obturator with light-cured resin system. J Indian Prosthodont Soc 2013;13(3):348-351. DOI: 10.1007/s13191-012-0159-0.
11. Venkatachalapathy SR, Chander GN, Gnanam P. A magnetically retained cheek plumper in a maxillary single complete denture: a clinical report. J Interdis Dentis 2019;9(1):25-30. DOI: 10.4103/jid. jid_37_18.

12. Patil PP, Madhav VN. Customised ball attachment retained cheek plumpers to enhance facial aesthetics: a case report. J Clin Diagn Res 2021;15(4):1-3.

13. Abdelbagi NF, Ismail IA, Awadalkreem F, et al. Detachable lip and cheek plumper for rehabilitation of facial disfigurement. Case Rep Dent 2021;21:1-6. 